site at $16 \mathrm{q} 22$ would develop the disease and have an inv(16) or del(16) in their malignant cells. Such families have not yet been found. Nor is it known whether individuals with haematological malignancies and other rearrangements at known fragile sites are carriers of a heritable fragile site on the altered chromosome. With respect to this possibility, the $t(8 ; 21)(q 22 ; q 22)$ is particularly intriguing because both a fragile site and a cellular oncogene (c-mos, the cellular counterpart of the oncogene of Moloney murine sarcoma virus) have been localized to $8 \mathrm{q} 22$ (ref.18). Ten of the twelve autosomes in the figure carry both an oncogene and a fragile site but only in the case of chromosome 8 are they coincident; the cellular oncogenes of chromosomes $6,8,9$ and 11 are in the same regions as the diseaserelated breakpoints, with c-myb on 6q15$\mathrm{q} 24, \mathrm{c}-$ mos on $8 \mathrm{q} 22, \mathrm{c}-m y c$ on $8 \mathrm{q} 24, \mathrm{c}-a b l$ on $9 \mathrm{q} 34$ and $\mathrm{c}-$ ras $^{\mathrm{H}-1}$ on $11 \mathrm{p} 15$ (ref.19).

While the structure of fragile sites is unknown, they presumably represent chromosomal segments which do not undergo normal compaction during mitosis. Whether this would serve to predispose the segments to rearrangement is an intriguing, but unanswered, question. More importantly, we are left with the basic questions of whether fragile sites act as predisposing factors for chromosomal rearrangements in human neoplasia and whether they carry genes whose functions are related to malignant transformation. In either case, the role of selection cannot be overlooked, because a particular rearrangement will result in clonal expansion only if it provides the affected cell with a growth advantage over normal cells.

1. Rowley, J.D. Nature 301, 290 (1983).

2. Sutherland, G.R. Am. J. hum. Genet. 31, 125 (1979)

3. Sutherland, G.R. Am. J. hum. Genet. 31, 136 (1979).

Sutherland, G.R. Int. Rev. Cytol. 81, 107 (1983)

Pearson, M.G. et al. Am. Soc. Hemat. 62, 180a (1983).

Rowley, J.D. Ann. Genet. 16, 109 (1973).

First int. Workshop on Chromosomes in Leukaemia $\mathrm{Br}$. J. Haemat. 39, 311 (1978).

8. Hagemeijer, A. et al. Cancer Genet. Cytogenet. 5, 95 (1982)

9. Rowley, J.D. \& Fukuhara, S. Semin. Oncol. 7, 255 (1980)

0. Third int. Workshop on Chromosomes in Leukemia Cancer Genet. Cytogenet. 4, 95 (1981).

Arthur, D.C. \& Bloomfield, C.D. Blood 61, 994 (1983)

12. LeBeau, M.M. et al. New Engl. J. Med. 309, 630 (1983)

13. Whang-Peng, J. et al. Science 215, 181 (1981).

14. Aurias, A. et al. New Engl. J. Med. 309, 496 (1983).

15. Turc-Carel, C. et al. New Engl. J. Med. 309, 497 (1983)

6. Yunis, J.J. Science 221, 227 (1983).

7. Arthur, D.C. \& Bloomfield, C.D. Am. Soc. Hemat. 62. $165 a(1983)$.

18. Neel, B.G., Jhanwar, S.C., Chaganti, R.S.K. \& Haywood, W.S. Proc. natn. Acad. Sci. U.S.A. 79, 7842 (1982).

19. Seventh int. Workshop on Human Gene Mapping Cytogenet. Cell Genet. 37, 1 (1984).

Michelle M. LeBeau and Janet D. Rowley are at the Department of Medicine, University of Chicago, Chicago, Illinois 60637.

\title{
Oceanography
}

\section{Sea-bed uplift by phase transition}

from Peter J. Smith

WHY should the depth of the ocean floor be proportional to the square root of the age $(t)$ of the lithosphere in regions of seafloor spreading only for lithosphere of up to about 70 Myr old? Beyond that, in most spreading zones, the ocean floor surface rises higher than the level predicted by the formula, so that for lithosphere $160 \mathrm{Myr}$ old the discrepancy is on average about $800 \mathrm{~m}$ (in about $6,000 \mathrm{~m}$ ).

A number of geophysical models have been proposed to account for this uplift, although only that of Crough (Tectonophysics 61,321 ; 1979), later developed by Heestand and Crough (J. geophys. Res. 86, $6107 ; 1981$ ), has hard data in its favour. One defect of all current geophysical models is that they take the oceanic lithosphere to be physically and chemically homogeneous, whereas, in other contexts, it is widely admitted to by anything but homogeneous. Thus most models assume a predominantly basaltic crust overlying a dry peridotite-rich upper mantle which may or may not include basaltic layers. It is likely that both the basaltic and peridotitic components of the lithosphere will undergo mineralogical and hence physical (especially density) changes as they cool. There seems to be a good case, therefore, for examining what effects such changes might have on ocean floor elevation in the context of the discrepancy between observation and the $t^{1 / 2}$ formula. Which is precisely what Wood and Yuen have now done with some success (Earth planet. Sci. Lett. 66, 303; 1983).

Given the uncertainties in lithospheric composition, the possibility of discontinuities in composition and the number of possible changes in mineralogy/petrology in both space and time, this is no easy task. Wood and Yuen therefore chose to concentrate on the phase transition from intermediate-pressure spinel lherzolite to high-pressure garnet lherzolite, a transition widely used to model lithospheric-upper mantle petrology. The spinel region is widely supposed to be the source of midoceanic ridge basalts and overlies the garnet region which is regarded as being close to undepleted mantle.

Because the spinel-garnet transition plays a crucial part in many oceanic lithospheric models, it has been extensively studied in the laboratory at high temperatures and pressures. In particular, there are now several sets of data, each showing that as temperature increases, pressure must also increase to allow the transition to take place. In short, the pressure-temperature boundary curve between the spinel and garnet fields has a positive gradient or Clapeyron slope. This is not very encouraging in the context of older cooler lithosphere, for, as Ito has shown (Earth planet. Sci. Lett. 21, 169; 1974), if the spinel-garnet transition occurs under circumstances in which the Clapeyron slope is positive, the effect will be to depress the ocean floor rather than elevate it. But, because the relationships between pressure and temperature have always been determined at temperatures above $850^{\circ} \mathrm{C}$ in order to work at practicable reaction rates, it has remained a possibility that the Clapeyron slope is negative at temperatures more appropriate to parts of the oceanic lithosphere.

To investigate that possibility, Wood and Yuen used a combined theoreticalexperimental technique developed by (the same) Wood and Holloway (J. geophys. Res. 87, A19; 1982) which essentially involves collection of complete thermodynamic data for each phase involved in the reaction and calculation of the stable mineral assemblage at each required temperature and pressure so that an equilibrium boundary can be pinned down. Wood and Yuen show that in the case of the spinel-garnet transition below about $850^{\circ} \mathrm{C}$, the Clapeyron slope is indeed negative.

Armed with the Clapeyron slope, the position of the spinel-garnet transition in the oceanic lithosphere can then be specified. Because, in the relevant temperature region, the Clapeyron slope is negative (that is, as the lithosphere cools and the temperature decreases, the pressure required to effect the spinelgarnet transition needs to be increased), the transition gets deeper with age in the period of interest ( $>70 \mathrm{Myr}$ ). Assuming isostatic compensation and conservation of mass in the lithosphere, it then becomes possible to determine the effect on topography.

It is easy to see what happens qualitatively. As the transition boundary drops with age, the thickness of the less dense spinel phase above the boundary will increase, and hence the level of the ocean floor will lie higher than it would in the absence of the phase transition. Numerically, however, there is no unique solution. The precise effect of the spinel-garnet transition on elevation will depend on the exact composition of the lithosphere, on thermal diffusivity and on the $\mathrm{Al}_{2} \mathrm{O}_{3}$ content of the lherzolite. But with reasonable ranges for all of these, Wood and Yuen conclude that the spinel-garnet transition could account for $50-300 \mathrm{~m}$ of the uplift relative to the $t^{1 / 2}$ curve at $160 \mathrm{Myr}$.

Although this is a significant proportion of the observed uplift, it is by no means the whole of it. But then Wood and Yuen are not ruling out contributions either from other phase transitions or from geothermal phenomena. What they have demonstrated is the important principle that the explanation of the elevation of older oceanic lithosphere can no longer be regarded as lying solely within the province of geodynamics.

Peter J. Smith is a Reader in the Department of Earth Sciences, The Open University, Milton Keynes MK $76 A A$, and editor of Open Earth. 